\title{
Immunohistochemical expression of latent membrane protein 1 (LMP1) and p53 in nasopharyngeal carcinoma: Moroccan experience
}

\author{
Tabyaoui $\mathrm{I}^{1}$, Serhier $\mathrm{Z}^{2}$, Sahraoui $\mathrm{S}^{3}$, Sayd $\mathrm{S}^{1}$, Cadi $\mathrm{R}^{4}$, Bennani $\mathrm{OM}^{2}$, Benider A $\mathrm{A}^{3}$, Zamiati $\mathrm{S}^{5}$, \\ *Tahiri Jouti $\mathrm{N}^{1}$
}

1. Pathology Laboratory, Faculty of Medicine and Pharmacy of Casablanca, Morocco.

2. Medical Informatics Laboratory, Faculty of Medicine and Pharmacy of Casablanca, Morocco.

3. Department of Oncology and Radiotherapy, Ibn Rochd University Medical Center, Casablanca, Morocco.

4. Physiology and Molecular Genetics Laboratory, Faculty of Sciences Aïn Chock, Casablanca, Morocco.

5. Department of Pathology, Ibn Rochd University Medical Center, Casablanca, Morocco.

\begin{abstract}
Background: Nasopharyngeal carcinoma (NPC) is a malignant epithelial tumor intimately associated with Epstein-Barr virus (EBV). NPC is a characteristic tumor displaying epidemiological, genetic and regional distribution properties that makes it unique by its natural behavior.

Objectives: To assess the expression pattern of LMP1 and p53 proteins in the different histological types of NPC in a sample of the Moroccan population and to define any association between the expression of those proteins with the sex, the age and the histological types of NPC.

Methods: Archival formalin-fixed, paraffin-embedded NPC biopsies were evaluated in 23 Moroccan patients for the presence of LMP1 and p53 using immunohistochemistry (IHC).

Results: No LMP1 expression was observed whereas 8 of 23 cases $(34.7 \%)$ had detectable p53 protein in the nuclei of tumor cells. After statistical analysis according to the Fisher's exact probability test, no significant association between p53 expression and histological type, age and sex distributions was demonstrated ( $\mathrm{p}>0.05)$.

Conclusion: This study confirms that p53 overexpression is present in a subset of Moroccan NPC patients. Our results are consistent with those reported by other studies concerning the same NPC endemic risk area and provide original data concerning Morocco.
\end{abstract}

Keywords: Epidemiology, Epstein-Barr virus, Immunohistochemistry, LMP1, Moroccan, Nasopharyngeal carcinoma, p53, Risk factors.

African Health Sciences 2013; 13(3): 710 - 717 http://dx.doi.org/10.4314/ahs.v13i3.27

\section{Introduction}

Nasopharyngeal carcinoma (NPC) is a malignant epithelial neoplasm with a remarkable geographic and racial distribution worldwide. Indeed, globally, there are three distinct endemic areas: an area with very high frequency in southern China (Canton), where the incidence is 30 to $80 / 100000 /$ year $^{1,2}$. An area of intermediate frequency (8 to $12 / 100$ 000/ year) in Taiwan, Vietnam, Thailand, Malaysia, the Philippines, the Caribbean, the Mediterranean (Maghreb and Middle East), Alaska and Greenland ${ }^{3}$. And finally an area of low frequency in North

*Corresponding author:
Professor Nadia Tahiri Jouti
Faculty of Medicine and Pharmacy, Pathology
Laboratory
Hassan II Aïn Chock University
19 rue Tarik Ibn Ziad - BP 9154
Casablanca, Morocco
Tel: +00 212666027559
E-mail: nadiatahirij@gmail.com

China, Europe and the United States (0.5 to 2/100 $000 /$ year $)^{4,5}$. In Morocco, the NPC incidence, estimated to be about 4.6/100 000/year and representing $5.3 \%$ of all cancers as reported by the Cancer Registry of the Casablanca Region (RCRC) published in 2007, is higher compared to Europe and $\mathrm{USA}^{6,7}$. In addition, the Moroccans in France are much more likely than French to be affected by the NPC and for the French who lived in North Africa, the incidence of NPC is 5.7 times greater than those lived in France 8 .

A male preponderance of nasopharyngeal carcinoma exists with a male-to-female ratio of approximately 2-3:19. While in South China, most NPC patients are between 40 and 60 years old, in North Africa, the distribution of NPC according to age is bi-modal. Beside the main peak of incidence around 50 years old ( $80 \%$ cases), there is a secondary peak between the age of 10 and 25 years old (juvenile form) $(20 \% \text { cases })^{10}$. 
The etiology of NPC is multifactorial and currently available data suggest a complex interplay of genetic, viral, environmental and dietary factors. Indeed, various human leukocyte antigens (HLA), such as HLA-A2, HLA-B17 and HLA-Bw46, are important etiologic or prognostic indicators in $\mathrm{NPC}^{11}$. As well, Epstein-Barr virus (EBV) is consistently detected in patients with nasopharyngeal carcinoma ${ }^{12,13}$, suggesting a role in the NPC pathogenesis. In intermediate to high risk Chinese populations, consumption of salted fish, especially during weaning in childhood, is associated with elevated risk of NPC ${ }^{14}$. The carcinogenic potential of salt-preserved food can be explained by the accumulation of significant levels of nitrosamines, which are known for their carcinogenic properties ${ }^{15}$. Salt-preserved fish also contain bacterial mutagens, direct genotoxins, and EBV-reacting substances, any or all of which could also contribute to the NPC risk $^{15}$.

In Maghrebian countries, associated foods include quaddid (dried mutton stored in oil), harissa (very spicy condiment prepared with red pepper, olive oil, garlic, caraway) and toklia (basic stewing preparation, contain red pepper, black pepper, garlic, salt, oil, caraway and coriander) in Tunisia, pickled fruit and vegetables, dried and salted fat, and rancid butter in Setif, Algeria, and rancid butter and khelii (dried meat, salty, spicy, cooked and preserved in a mixture of oil and melted bovine greases) in Morocco, have been suggested to be associated with increased NPC risk ${ }^{16}$.

Other environmental factors such as tobacco, cannabis and domestic cooking fumes intake (cooking in the main living room) during childhood, have recently been described as a risk factors for NPC in North African countries ${ }^{17}$. Furthermore, a study subdividing Morocco into three zones of variable incidence of NPC (North-Rif-Oriental, Center-Middle Atlas, Haouz-South) revealed the existence of a south-north gradient of exposure to presumed risk factors, essentially bad living conditions, food preservation agents and poor hygiene ${ }^{18}$. Lower socio-economic level has also been reported as an important confounding factor for NPC in China, Greenland and Tunisia ${ }^{19}$.

Epstein-Barr virus is a lymphotropic human gamma herpesvirus which infects more than 90\% individuals in the human population ${ }^{20}$. EBV has been classified as a type I carcinogen by the World Health Organization (WHO) due to its etiological implication in the pathogenesis of several human malignancies including Burkitt's and Hodgkin's lymphomas, gastric carcinoma and NPC ${ }^{21}$. EBV infection in NPC is classified as type II latent infection in which only EBV nuclear antigen-1(EBNA-1), latent membrane protein-1(LMP1), LMP2, and EBV early RNA (EBER) expressions can be detected ${ }^{22}$. Studies of normal nasopharyngeal tissue and premalignant biopsies indicate that genetic events, loss of heterozygosity at chromosomes $3 p$ and $9 p$, occur early in the pathogenesis of NPC, possibly as a result of exposure to environmental cofactors such as dietary components (salted fish), and that this might predispose to subsequent EBV infection ${ }^{23}$. Once cells have become infected, EBV latent genes provide growth and survival benefits, resulting in the development of NPC 23. Among the molecules of EBV latency, LMP1 (Latent membrane protein 1) is the main oncogene of EBV because of its ability to recruit an array of cellular genes and to inhibit apoptosis by elevating Bcl-2 levels ${ }^{21,22,24}$

The p53 gene (TP53) is a tumor suppressor gene frequently mutated in diverse malignant tumors. It is codes for a $53-\mathrm{kD}$ a cellular protein that leads to the cell cycle arrest in G1 phase, after DNA damage, in order to repair DNA or mediate cell apoptosis ${ }^{25}$. Several studies have reported that, in NPC cases, a high percentage of $\mathrm{p} 53$ protein expression were detected by immunohistochemistry (IHC) ${ }^{26}$. Overexpression of p53 is usually due to mutant p53, which has a longer half-life as a result of decreased degradation of the protein ${ }^{27}$. Interestingly, for NPC, other factors such as EBV may contribute to p53 protein overexpression.

In North Africa, contrasted frequencies of p53 accumulation in NPC were observed with regard to the age distribution: there was significantly much less p53-positive tumors in the group of young patients (juvenile forms) than in the main age group (above 30 years of age) ${ }^{28}$.

The aim of this study was to investigate the expression of LMP1 and $\mathrm{p} 53$ proteins in the different histological types of NPC in a sample of the Moroccan population. We also attempted to define any association between the expression of those proteins with the sex, the age and the histological types of NPC. To this end we used immunohistochemical technique on formalin fixed, paraffin wax embedded tissue. 


\section{Methods \\ Patients}

23 cases of formalin-fixed, paraffin-embedded tissue blocks of nasopharyngeal carcinoma diagnosed in 2005 were retrieved from the archives of Department of Pathology, Ibn Rushd University Medical Center, Casablanca, Morocco. All patients were diagnosed, treated and followed up at the Oncology and Radiotherapy Department of the Ibn Rushd University Medical Center. Clinical and pathological aspects such as age, sex and histological types were abstracted from reports and clinical records.

\section{Histology classification}

The histological classification of nasopharyngeal carcinoma proposed by the World Health Organisation (WHO) in 1978, categorized tumours into three groups based on their degrees of differentiation ${ }^{11}$ : type I (WHO-1) is keratinising squamous-cell carcinomas (SCC), type II (WHO-2) is non-keratinising squamous carcinomas (NKC) and type III (WHO-3) is typical undifferentiated carcinomas (UC). An alternative classification has divided tumours into two histological types, namely squamous-cell carcinomas (WHO type I) and undifferentiated carcinomas of the nasopharyngeal (WHO types II and III) ${ }^{12,29}$.

\section{Immunohistochemical staining for LMP1 and p53 proteins}

LMP1 and p53 staining was performed on 23 NPC specimens. The LSAB detection system (ScyTek kit) was employed to detect the expression of both proteins. Briefly, a 4- $\mu \mathrm{m}$-thick section was cut from each paraffin archival block and mounted on treated slides. After heating at $60{ }^{\circ} \mathrm{C}$ for $30 \mathrm{~min}$, the tissue sections were dewaxed in toluene, rehydrated in ethanol and rinsed in distilled water for $5 \mathrm{~min}$. Antigen availability for p53 was enhanced by pretreatment for 30 minutes at $99^{\circ} \mathrm{C}$ in Tris-EDTA buffer, $\mathrm{pH} 9$.

For both proteins, endogenous peroxidase was quenched with $\mathrm{H}_{2} \mathrm{O}_{2}$ for $10 \mathrm{~min}$ and nonspecific binding was blocked with protein blocker for $5 \mathrm{~min}$. Sections were incubated with primary antibody for 30 min. Primary antibodies used in this study were anti-LMP1 (1:100 dilution) (clone CS1-4, Dako) and anti-p53 protein (1:50 dilution) (clone DO-1, Immunoteck) which reacts with both wild and mutant types of $\mathrm{p} 53$ protein. Immunobinding of
anti-LMP1 and p53 was visualized with biotinlabeled secondary antibodies and streptavidineperoxidase complexes with use of diaminobenzidine 'DAB' as a chromogenic substrate (DAB Chromogenic kit, ScyTek). Sections were counterstained with Harris hematoxylin, which enhanced visualization of tissue architecture and cytological details, and mounted with Eukitt.

A Hodgkin's disease EBV-induced and squamous cell carcinoma of cervix tissue sections known to be immunoreactive for LMP1 and p53 staining respectively, was included in every batch as an external positive control. Negative controls were performed by substituting the primary antibody with an antibody diluent in parallel assays of each tumor. The LMP1 and p53 were localized and quantitated by microscopic evaluation of cytoplasmic and nuclear staining respectively.

\section{Analysis of LMP1 and p53 reactivity}

LMP-1 expression was considered positive when more than $10 \%$ of neoplastic cells showed a membrane pattern of staining and p53 expression was considered positive if nuclear staining was found in more than $10 \%$ of neoplastic cells.

\section{Statistical analysis}

Statistical significance among categorical data was evaluated using the Fisher's exact probability test. Probability values less than 0.05 were considered to be significant. LMP1 and p53 expressions were analyzed as qualitative variables, according to various clinicopathological parameters. The statistical analyses were performed using Epi-Info 3.5.1 software.

\section{Results}

\section{Clinical and histological data}

The male: female ratio was 2.28:1, with 16 men and 7 women. The ages were ranged between 10 and 68 years (mean age, $42 \pm 16.47$ years). Age was not specified for two patients.

23 primary NPC cases consisted of 7 cases $(30.4 \%)$ of differentiated nonkeratinizing carcinoma (NKC, WHO type 2) and 16 cases (69.6\%) of undifferentiated carcinoma (UC, WHO type 3) according to World Health Organization classification. No cases of keratinized squamous cell carcinoma (SCC, WHO type 1) have been reported. 
Table 1: p53 protein detection in NPC specimens: correlation with clinical and histopathological data

\begin{tabular}{|c|c|c|c|c|}
\hline \multirow{2}{*}{$\begin{array}{l}\text { Correlative } \\
\text { data }\end{array}$} & \multirow{2}{*}{$\begin{array}{l}\text { Specimens } \\
\text { No. (\%) }\end{array}$} & \multicolumn{2}{|c|}{$\begin{array}{l}\text { Immunohistochemical } \\
\text { expression of p53 protein }\end{array}$} & \multirow[t]{2}{*}{ P value* } \\
\hline & & Negative $n(\%)$ & Positiven (\%) & \\
\hline \multicolumn{5}{|l|}{$\begin{array}{l}\text { Sex } \\
\end{array}$} \\
\hline Male & 16 (69.6) & $10(62.5)$ & $6(37.5)$ & 0.53 \\
\hline Female & 7 (30.4) & $5(71.4)$ & 2 (28.6) & \\
\hline \multicolumn{5}{|l|}{ Age (years) } \\
\hline$<30$ & $5(23.8)$ & $5(100)$ & $0(0)$ & 0.06 \\
\hline$>30$ & $16(76.2)$ & $8(50)$ & $8(50)$ & \\
\hline \multicolumn{5}{|c|}{ Histological type } \\
\hline SCC & $0(0)$ & $0(0)$ & $0(0)$ & \\
\hline NKC & 7 (30.4) & $4(57.1)$ & $3(42.9)$ & 0.46 \\
\hline UC & $16(69.6)$ & $11(68.8)$ & $5(31.3)$ & \\
\hline
\end{tabular}

\section{LMP1 expression}

Immunohistochemical analysis for EBV encoded LMP-1 expression in 23 NPC cases did not reveal any positive immunostaining. The negative control showed no immunoreactivity (LMP1 negative). The positive control showed LMP1 reactivity manifested by a cytoplasmic staining of Reed Sternberg cells specific for Hodgkin's disease. No background was detected.

\section{p53 expression}

An immunohistochemical staining method was used to identify and measure p53 expression. Among 23 examined specimens, $8(34.8 \%)$ showed positive staining for the p53 protein and $15(65.2 \%)$ showed no detectable p53 protein in tumor cells. As previously reported for NPC, the p53 staining was restricted to the nuclei of tumor cells, no cytoplasmic staining was observed (figure 1). The intensity of immunostaining was heterogeneous among tumor nuclei: some were strongly labeled, others were less. The pattern of labeling intensity was also variable among cases: some cases only showed some intensely immunostained cells while others showed positive cells scattered throughout the tumor cell nest.

Table 2: Variation of the expression of p53 expression according to NPC endemic areas risk in the World

\begin{tabular}{llll}
\hline & Taiwan & Morocco & Greece \\
\hline NPC endemic risk & high & intermediate & low \\
p53 expression (\%) & $95[38]$ & 34.7 & $15.9[33]$ \\
\hline
\end{tabular}
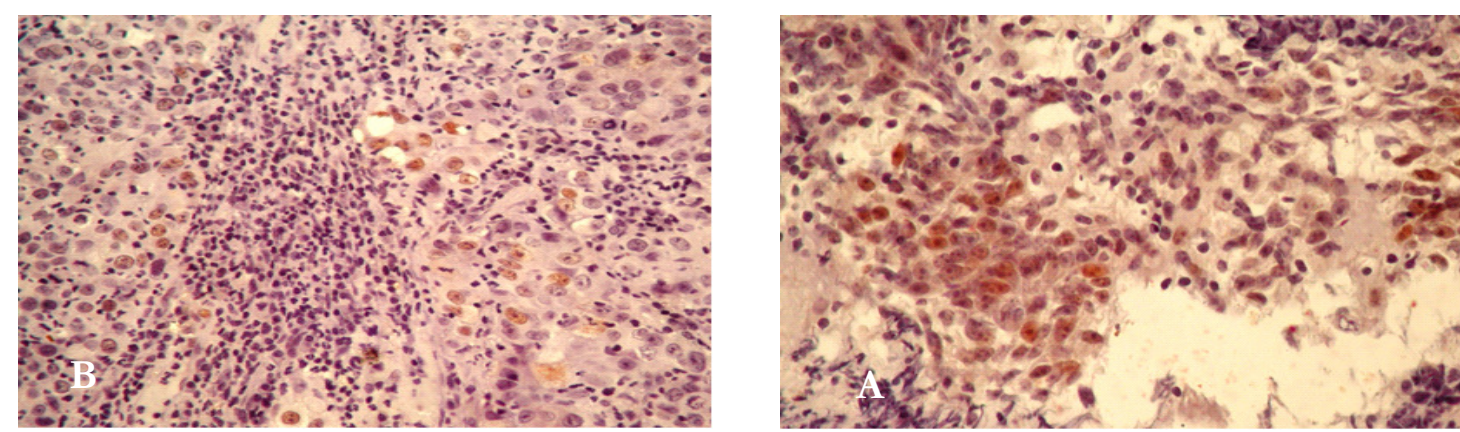

Figure 1: p53 protein staining on: A/ positive control (squamous cell carcinoma of cervix cancer) B/ tissue section of a NPC biopsy. Immunohistochemical staining with light Harris hematoxylin counterstain. $(400 \mathrm{x})$ 
The correlations between p53 expression and histological type, age, and sex distribution were tested and are summarized in table 1 . Among the p53positive patients, $37.5 \%$ were men and $28.6 \%$ were women $(P>0.05)$. All the patients overexpressing the p53 protein were older than 30 years old $(P=$ 0.06). By correlating p53 expression with histopathological type, positive staining was observed in 3 of $7(42.9 \%)$ nonkeratinizing carcinomas and in 5 of $16(31.3 \%)$ undifferentiated carcinomas $(P$ $>0.05)$.

\section{Discussion}

The data we reported may not reflect the situation in the general population, especially as we worked on a size-reduced series (23 cases), but our results are in keeping with those previously reported. In fact, we found that males were more affected by nasopharyngeal cancer than females $(69.5 \%$ versus $30.4 \%$ respectively) with a sex ratio of 2.28 . This was consistent with other previous data where the sex ratio ranged between 2 and 3.5 for $\operatorname{men}^{30}$. A previous Moroccan study also reported a sex ratio of $2.44^{8}$. Several epidemiological studies have revealed a bimodal pattern for North African NPCs. Whereas in Southeast Asia there is only one single peak of incidence about the age of 50 years, in North Africa an additional minor peak of incidence occurs between the ages of 10-20 years, including around $15 \%$ of all NPC patients ${ }^{10,30,31}$. Our study showed a maximum NPC frequency in older patients, but unlike other studies in North Africa, we couldn't highlight the second peak corresponding to juvenile forms. This was probably due to the fact that the 23 patients diagnosed were mostly adults as confirmed by the mean age of our series (42 years).

We also noticed a predominance of undifferentiated carcinomas (UC, WHO type III) $(69.5 \%)$ compared with non-keratinising carcinomas (NKC) (30.4\%), whereas keratinising squamous-cell carcinomas (SCC, WHO type II) were non-existent. This was quite logical considering that Morocco is a NPC intermediate risk area and that, in those regions, the vast majority of NPC belongs to the most undifferentiated forms, namely WHO types II and $\mathrm{III}^{30}$.

Through this work, we studied for the first time in Morocco the expression of LMP1 protein and overexpression of $\mathrm{p} 53$ protein in NPC patients.

We have not detected the presence of LMP1 in our sample, unlike other studies that have reported its expression in $50 \%$ to $65 \%$ of EBV-positive NPC cells $^{29}$. An immunohistochemical detection of LMP1 performed on 52 Spanish patients showed a positivity of $78.4 \%{ }^{32}$, what was inconsistent with another study where a single LMP1 positive case belonging to the undifferentiated NPC (WHO type 3) have been detected on a series of 44 cases $^{33}$. The non-detection of LMP1 disallowed us from establishing any association between this protein expression and other clinicopathological parameters. However, we can attribute the lack of LMP1 expression in our series to various reasons. First, there are differences in technical procedures which could explain the heterogeneity of results: indeed it is reported that the immunohistochemical technique may be less sensitive than Western blot $(65 \%$ of positivity) or RT-PCR (approximately 100\% of expression) for the detection of $\mathrm{LMP}^{34}$. Some authors also take into consideration the quality of the used anti-LMP1 clone; it appears that S12 or anti-136 clones provide better results in terms of sensitivity than the CS 1-4 clone ${ }^{10}$. This also can be due to a limitation of the immunohistochemical technique on fixed tissue, since some studies have reported $20-30 \%$ of LMP1 responsiveness on NPC frozen tissues versus $0 \%$ of expression in paraffinembedded tissues $^{33}$. Another possible reasons such as the adopted detection threshold ${ }^{10}$, the methylation phenomenon of the LMP1 genome that plays an important role in this gene regulation in NPC tumors $^{35}$, the existence of various subsets of LMP1 with different transformation abilities ${ }^{36,37}$ or the restriction of the LMP1 expression to some unknown stages of NPC development may also explain this non-detection of LMP1 expression in our series.

Support for the possible role of p53 in carcinogenesis comes from a series of observations made in NPCs and in other types of cancer. In normal cells, the p53 protein had a very short halflife. By contrast, p53 gene mutations generally lead to stabilization of the protein (a longer half-life), which can be detected by immunohistochemistry, a very simple, fast and reliable standardized method commonly used in the studies of $\mathrm{p} 53$ overexpression.

In our study, p53 was expressed in $34.7 \%$ of cases $(8 / 23)$. This percentage was higher than that of a Greek study where $15.9 \%$ of reactivity was observed ${ }^{33}$ but lower than other study conducted in Taiwan where the positivity of p53 was estimated at $95 \%{ }^{38}$. This difference in p53 expression levels cannot be entirely explained by the antibody clone used since, although we used the DO- 
1 clone while the majority of the studies carried out used the anti-p53 DO-7 clone, a comparative research have shown that these two antibody clones had the same detection sensitivity and specificity ${ }^{39}$. However, this work, that have evaluated seven monoclonal antibodies against $\mathrm{p} 53$, also showed that the 1801 clone used in the Taiwanese study, was less sensitive and less specific than both DO-1 and DO7 antibodies $^{39}$. On the other hand, the disparity of p53 expression results between these three studies may suggest a biological variability of tumors according to geographical location and we could talk about a p53 expression frequency depending of the NPC endemic areas (table 2), since in Taiwan which is a highly NPC endemic area, a significant overexpression of p53 was observed compared to Morocco (NPC intermediate risk) and to Greece where the NPC is lowly endemic.

A study achieved by Khabir et al. showed that there was an accumulation of $\mathrm{p} 53$ protein depending of the age: indeed in North African population, this protein was highly expressed $(81 \%)$ in elderly patients (e" 30 years) compared with patients under 30 years $(38 \%)$. This difference in p53 expression between the two age groups may be due to the fact that patients under 30 years have only one or two copies of EBV genome per malignant cell whereas this number is much higher in adults (an average of 10 copies of EBV genome per malignant cell). This tends to prove the existence of $\mathrm{p} 53 / \mathrm{EBV}$ interactions and suggests that NPC cells use, for the two age groups, two distinct pathways to escape to apoptosis and continue their malignant transformation. In our study, all patients who expressed p53 had more than 30 years, however it wasn't a significant association $(p=0,06)$, probably due to the lack of power of the statistical test resulting from the small sample size. Regarding histological types, we found no significant difference between the p53 overexpression and the degree of NPC differentiation $(p=0,46)$. Other studies also showed no correlation between p53 expression and histological type, stage, age and sex distributions of NPC ${ }^{38,40}$.

The majority of the studies on p53 genetic abnormalities in human cancers focused on exons 5 to 8 , the mutation 'hot-spot' region which codes for the DNA binding domain of p53 protein ${ }^{41}$. However, in nasopharyngeal carcinoma, nearly all studies on p53 gene alterations reported a low percentage (less than $20 \%$ ) or absence of mutation in NPC tumor tissues ${ }^{42,43}$ although p53 protein was overexpressed ${ }^{28}$. As well, a recent study on 53 NPC samples found no mutation in exons 5 to 8 of p53 protein, despite $87 \%$ of them having high intensity of p53 expression ${ }^{44}$. This finding of p53 accumulation in NPC tissues, in the absence of a mutation in the 'hot-spot' region of the gene, established that high expression of its protein in NPC cells was not associated with mutation in the p53 DNA-binding domain ${ }^{44}$.

Indeed, stabilization of the p53 may also be achieved through the formation of complexes between cellular gene product or viral oncoprotein and wildtype p53 protein ${ }^{45}$.

It has already been shown that the p53 protein can bind to cellular proteins, such as the mdm2 oncogene product and heat-shock protein 70 and to several DNA tumor virus proteins, including SV40 $\mathrm{T}$ antigen and E1b protein from adenovirus type 5, leading to its stabilized accumulation and inactivation ${ }^{38,40}$. Moreover, the ability of EBV and its genes products in stabilizing or accumulating p53 protein cannot be ignored, fact confirmed by the highly significant association between EBV infection and p53 overexpression in NPC and the presence of EBV-encoded proteins that can bind and inactivate the $\mathrm{p} 53$ oncoprotein ${ }^{45,46,47}$. Thus, it is possible that one or multiple EBV genes products interact with p53 and ultimately cause its nuclear accumulation. This possibility is supported by many studies identifying two EBV proteins, BZLF1 and EBNA5, which are capable of binding p53 protein ${ }^{46,47}$. Of these two proteins, EBNA5 has not been detected in NPCs, whereas a direct interaction between BZLF1 protein and $\mathrm{p} 53$ protein has been demonstrated. Hence, overexpression of wild-type p53 protein inhibits the ability of BZLF1 protein to disrupt viral latency; likewise BZLF1 protein inhibits $\mathrm{p} 53$-dependent trans-activation ${ }^{45}$. Thus, in the NPC cells, p53 is detected in the wildtype configuration and would be probably inactivated by binding to EBV viral proteins resulting in its nuclear accumulation and probable compromised function.

Further investigation, using other techniques, of the molecular and biological changes that occur during carcinogenesis and progression of NPC can provide new insight into the pathology of this disease in Morocco and could add biological factors that can be used as new prognostic markers. 


\section{Conclusion}

This study confirms that p53 overexpression is present in a subset of Moroccan NPC patients. Our results are consistent with those reported by other studies concerning the same NPC endemic risk area and provide original data concerning Morocco.

\section{References}

1. Yu MC, Yuan JM. Epidemiology of nasopharyngeal carcinoma. Semin Cancer Biol 2002; 12: 421-429.

2. Stewart BW, Kleihues P. World Cancer Report chap. Head and neck cancer. Lyon, IARC Press. 2003; p: 322.

3. Seigneurin JM, Fafi-Kremer S, Baccard M, Morand P. Cahier de formation biologie médicale: Le virus Epstein-Barr et les marqueurs de l'infection 2006; $\mathrm{N}^{\circ}: 36$.

4. Brennan B. Nasopharyngeal carcinoma. OJRD 2006; 1: 23.

5. Busson P, Ooka T, Corbex M. Carcinomes nasopharyngés associés au virus d'Epstein-Barr : De l'épidémiologie à la thérapeutique et au dépistage. M/S : médecine sciences 2004; 20 (4): 453457.

6. El Gueddari B, Chaouki N. Approche épidémiologique descriptive du cancer au Maroc à travers l'activité de l'Institut National d'Oncologie. (1986-1987). Bull cancer 1991; 78: 603-609.

7. Registre des Cancers de la Région du Grand Casablanca (RCRC): Année 2004. Edition Association Lalla Salma de lutte contre le Cancer, 2007.

8. Arfaoui A, Soulaymani A, Quyou A, Habib F. Choulli MK. Le cancer du cavum au Maroc. Etude épidémiologique sur l'échantillon: Centre d'oncologie Al Azhar de Rabat. Antropo 2007; 14: 75-82.

9. Hasbini A, Raymond E, Cvitkovic E, Eschwège F, Armand JP. Les cancers des voies aérodigestives supérieures : Les carcinomes du nasopharynx. B Cancer 2000; 87: 21-26.

10. Khabir A, Karray H, Rodriguez S et al. EBV latent membrane protein 1 abundance correlates with patient age but not with metastatic behavior in North African nasopharyngeal carcinomas. Virology 2005; 2: 39.

11. Thompson LDR. Update on Nasopharyngeal Carcinoma. Head and Neck Pathol 2007; 1: 8186.
12. Wei WI, Sham JST. Nasopharyngeal carcinoma. Lancet 2005; 365: 2041-2054.

13. Chang ET, Adami HO. The enigmatic epidemiology of nasopharyngeal carcinoma. Cancer Epidemiol Biomarkers Prev 2006; 15 (10): 1765-1777.

14. Yuan JM, Wang XL, Xiang, Gao YT, Ross RK, $\mathrm{Yu}$ MC. Preserved foods in relation to risk of nasopharyngeal carcinoma in Shanghai, China. Int J Cancer 2000; 85: 358-363.

15. Tabuchi K, Nakayama M, Nishimura B, Hayashi K, Hara A. Early detection of nasopharyngeal carcinoma. Int J Otolaryngol 2011, Article ID 638058, 6 pages.

16. Feng BJ, Jalbout M, Ayoub WB et al. Dietary risk factors for nasopharyngeal carcinoma in Maghrebian countries. Int J Cancer 2007; 121 (7): 1550-1555.

17. Feng BJ, Khyatti M, Ben-Ayoub W et al. Cannabis, tobacco and domestic fumes intake are associated with nasopharyngeal carcinoma in North Africa. Brit J Cancer 2009; 101: $1207-$ 1212.

18. Ammor S, Baali A, Cherkaoui M, Hubert A. Facteurs alimentaires et environnementaux de risque du cancer du rhino-pharynx au Maroc et leur répartition géographique, Bulletins et Mémoires de la Société d'Anthropologie de Paris 2005 ; Tome 17, Fascicule 1-2.

19. Jeannel D, Bouvier G, Hubbert A. Nasopharyngeal carcinoma: an epidemiological approach to carcinogenesis. Cancer Surv 1999; 33: 125-155.

20. Yang L, Lu Z, Ma X, Cao Y, Sun LQ. Therapeutic Approach to nasopharyngeal carcinomas by DNAzymes targeting EBV LMP-1 gene. Molecules 2010; 15: 6127-6139.

21. Kieser A. Signal transduction by the EpsteinBarr virus oncogene latent membrane protein 1 (LMP1). Signal Transduction 2007; 7: 20-33.

22. Korcum AF, Özyar E, Ayhan A. Epstein-Barr virus genes and nasopharyngeal cancer. Turk $J$ Cancer 2006; 36 (3): 97-107.

23. Young LS, Rickinson AB. Epstein - Barr virus: 40 years on. Nature 2004; 4: 757-768.

24. Thompson MP, Kurzrock R. Epstein-Barr Virus and Cancer. Clin Cancer Res 2004; 10: 803-821.

25. Bernardini S, Chabannes E, Bittard H. Utilité du p53 dans la prise en charge clinique des tumeurs vésicales. Prog Urol 2001; 11: 201-208. 
26. Taweevisit M. Overexpression of p53 and neoplastic cellproliferation in undifferentiated nasopharyngeal carcinoma. Southeast Asian J Trop Med Public Health 2007; 38 (1): 136-140.

27. Cadwell C, Zambetti GP. The effects of wildtype p53 tumor suppressor activity and mutant p53 gain-of-function on cell growth. Gene 2001; 277: 15-30.

28. Khabir A, Sellami A, Sakka M et al. Contrasted Frequencies of p53 Accumulation in the Two Age Groups of North African Nasopharyngeal Carcinomas. Clin Cancer Res 2000; 6: 3932-3936.

29. Chan ATC, Teo PML, Johnson PJ. Nasopharyngeal carcinoma. Ann Oncol 2002; 13: 1007-1015.

30. Rivera S, Keryer C, Busson P, Maingon P. Les carcinomes du nasopharynx : de la biologie à la clinique. Cancer/Radiothérapie 2005; 9: 55-68.

31. Centre International de Recherche sur le Cancer (CIRC). Données épidémiologiques sur le NPC 2004.

32. Vera-Sempere FJ, Burgos JS, Botella MS, Cordoba J, Gobernado M. Immunohistochemical expression of EpsteinBarr virus-encoded membrane protein (LMP1) in paraffin sections of EBV-associated nasopharyngeal carcinoma in Spanish patients. Oral Oncol, Eur J Cancer B 1996; 32 (3): 163-168.

33. Kouvidou Ch, Kanavaros P, Papaioannou D et al. Expression of bcl-2 and p53 proteins in nasopharyngeal carcinoma. Absence of correlation with the presence of EBV encoded EBERl-2 transcripts and latent membrane protein-1. J Clin Pathol: Mol Pathol 1995; 48 :1722.

34. Niedobitek G. Epstein-Barr virus infection in the pathogenesis of nasopharyngeal carcinoma. J Clin Pathol: Mol Pathol 2000; 53: 248-254.

35. Hu LF, Minarovits J, Cao SL et al. Variable expression of Latent Membrane Protein in nasopharyngeal carcinoma can be related to methylation status of the Epstein-Barr Virus BNLF-1 5'-flanking region. J Virol 1991; 65 (3): 1558-1567.

36. Edwards RH, Sitki-Green D, Moore DT, RaabTraub N. Potential Selection of LMP1 Variants in Nasopharyngeal Carcinoma. J Virol, 2004; 78 (2): 868-881.
37. Mainou BA, Raab-Traub N. LMP1 strain variants: biological and molecular properties. $J$ Virol, 2006; 80 (13): 6458-6468.

38. Sheu L, Chen A, Tseng HH et al. Assessment of p53 Expression in Nasopharyngeal Carcinoma. Hum Pathol 1995; 26: 380-386.

39. Bonsing BA, Corver WE, Gorsira MC, van Vliet M, Oud PS, Cornelisse CJ, Fleuren GJ. Specificity of seven monoclonal antibodies against p53 evaluated with Western blotting, immunohistochemistry, confocal laser scanning microscopy, and flow cytometry. Cytometry 1997; 28(1): 11-24.

40. Agaoglu FY, Dizdar Y, Dogan O et al. p53 Overexpression in Nasopharyngeal Carcinoma. In Vivo 2004; 18 (5): 555-560.

41. Petitjean A, Achatz MI, Borresen-Dale AL, Hainaut P, Olivier M. TP53 mutations in human cancers: functional selection and impact on cancer prognosis and outcomes. Oncogene 2007; 26: 2157-2165.

42. Sun Y, Hegamyer G, Cheng YJ et al. An infrequent point mutation of the p53 gene in human nasopharyngeal carcinoma. Proc Natl Acad Sci 1992; 89: 6516-6520.

43. MacGeoch C, Barnes DM, Newton JA et al. p53 protein detected by immunohistochemical staining is not always mutant. Dis Markers 1993; 11: 239-250.

44. Hoe SLL, Lee ES, Khoo ASB, Peh SC. p53 and nasopharyngeal carcinoma: a Malaysian study. Pathology 2009; 41 (6): 561-565

45. Murono S, Yoshizaki T, Park CS, Furukawa M. Association of Epstein-Barr virus infection with p53 protein accumulation but not bcl-2 protein in nasopharyngeal carcinoma. Histopathology 1999; 34: 432-438.

46. Gulley ML, Burton MP, Allred DC et al. EpsteinBarr Virus infection is associated with p53 accumulation in nasopharyngeal carcinoma. Hum Pathol 1998; 29: 252-259.

47. Yip KW, Shi W, Pintilie M et al. Prognostic significance of the Epstein-BarrVirus, p53, Bcl2 , and survivin in nasopharyngeal cancer. Clin Cancer Res 2006; 12 (19): 5726-5732. 